\title{
Características agronômicas associadas com índices de vegetação medidos por sensores ativos de dossel na cultura da soja
}

\section{Agronomic characteristics associated with vegetation index measured by active sensors of the canopy in soybean}

\author{
Edson Cristiano Groff ${ }^{1 *}$; Marcos Rafael Nanni ${ }^{2}$; \\ Fabrício Pinheiro Povh ${ }^{3}$; Everson Cezar ${ }^{4}$
}

\begin{abstract}
Resumo
A soja sempre se destacou pela sua importância econômica no cenário agrícola nacional tendo sido observado aumento do seu cultivo em todo o território brasileiro. Com o uso crescente da agricultura de precisão (AP) é de suma importância entender a variabilidade das variáveis agronômicas. Atualmente, sensores espectrais em nível terrestre vêm sendo utilizados para estabelecer relações entre as respostas espectrais e parâmetros de crescimento da cultura. Isso é possível por meio da leitura dos índices de vegetação, como o Índice de Vegetação da Diferença Normalizada utilizando a banda verde (GNDVI). Este estudo foi conduzido entre outubro de 2008 e abril de 2009, em Ponta Grossa - PR, com o objetivo de avaliar a resposta espectral da cultura da soja por meio do GNDVI e sua correlação com algumas variáveis agronômicas, como: produtividade de grãos, produtividade de massa seca, densidade de plantas e altura de plantas. Leituras do GNDVI foram realizadas em seis estádios fenológicos (EF) utilizando o sensor óptico ativo Crop Circle. Análises de regressão foram utilizadas para determinar quais variáveis agronômicas estabeleciam relação com o GNDVI. O GNDVI na cultura da soja estabeleceu correlações significativas apenas com a produtividade de grãos e a produtividade de MS no EF V9. Assim, para se estabelecer a correlação do GNDVI com essas variáveis recomenda-se que as leituras sejam realizadas nesse EF.
\end{abstract}

Palavras-chave: Índice de vegetação, resposta espectral e sensoriamento remoto

\begin{abstract}
Soybean has always stood out for its economic importance in the national agricultural scenario with an increase in its cultivation throughout the Brazilian territory. With the increasing use of precision agriculture (PA) is of paramount importance to understand the variability of agronomic variables. Currently, spectral sensors in the ground-level have been used to establish relationships between spectral response and crop growth parameters. This is possible through the reading of vegetation indices such as Normalized Difference Vegetation Index using the green band (GNDVI). This study was conducted between October to 2008 and April to 2009, in Ponta Grossa - PR, with the objective of evaluating the spectral response of soybean through GNDVI and its correlation with some agronomic variables, such as: productivity of grain, productivity of dry mass, plant density and plant height. GNDVI readings were taken on six phenological stages using Crop Circle active optical sensor. Regression analyzes were used to determine which agronomic variables established relationship with the GNDVI. The GNDVI
\end{abstract}

${ }^{1}$ Eng $^{\mathrm{o}}$ Agr ${ }^{\circ}$, MSc. em Agronomia pela Universidade Estadual de Maringá, UEM, Maringá, PR. E-mail: ecgroff@hotmail.com

2 Prof. Dr. Dept ${ }^{\circ}$ Agronomia, UEM/CCA, Maringá, PR. E-mail: mrnanni@uem.br

3 Eng ${ }^{\circ}$ Agr $^{\circ}$ Dr. Coordenador na área de Agricultura de Precisão da Fundação ABC, Castro, PR. E-mail: fabricio@fundacaoabc. org.br

4 Discente de Doutorado em Agronomia, UEM, PR. E-mail: eversoncezar@yahoo.com.br

* Autor para correspondência 
in soybean established significant correlations only with grain and MS productivity in EF V9. Thus, to establish the correlation of GNDVI with these variables it is recommended that the readings are carried out in this EF.

Key words: Vegetation index, spectral responses, remote sensing

\section{Introdução}

A cultura da soja (Glycine $\max$ L. Merrill) destaca-se pela grande importância econômica nacional e pelo crescimento do cultivo nos últimos anos em todo território brasileiro. Na safra 2011/2012, a área cultivada no Brasil foi de 25,04 milhões de hectares, $3,6 \%$ superior à cultivada na safra anterior (CONAB, 2012).

A utilização de técnicas de sensoriamento remoto na agricultura tem sido relatada desde a década de 60 , para o mapeamento de solos e a previsão de safras, com o uso de fotografias aéreas. Posteriormente, começaram a ser utilizadas imagens de satélites no monitoramento das áreas (FONTANA et al., 2002; SUGAWARA; RUDORFF; ADAMI, 2008), na previsão de safras e na avaliação do desenvolvimento das plantas (MOTTA; FONTANA; WEBER, 2001; ALMEIDA, 2008). O sensoriamento remoto tem sido considerado uma ferramenta importante em vários aspectos relacionados à agronomia principalmente no estudo do solo e da vegetação (GENÚ; DEMATTÊ; FIORIO, 2010).

Atualmente, também são utilizados sensores terrestres que permitem estabelecer relações entre as respostas espectrais do solo (NANNI; DEMATTÊ; FIORIO, 2004), da cultura e os parâmetros de crescimento das plantas (FORMAGGIO e EPIPHANIO, 1998). Isto é possível por meio da leitura de índices de vegetação, como o índice de vegetação da diferença normalizada utilizando a banda verde (GNDVI) conforme propõe (SHANAHAN et al., 2001). Estes índices possibilitam analisar a distribuição espacial das áreas cultivadas, mapear as diferenças de vigor das plantas, melhorar o direcionamento das amostragens e observações de campo promovendo, assim, melhor avaliação do potencial de produção (MACHADO, 2003).
Com o crescente uso da agricultura de precisão (AP), a compreensão da variabilidade das variáveis agronômicas, que compõem o sistema de produção se torna fundamental. Além disso, as restrições ambientais e a capacidade de uso do solo geram a necessidade de adoção de tecnologias que possibilitem maximizar a produtividade.

Neste sentido, o trabalho foi conduzido com o objetivo de avaliar a correlação do GNDVI com as variáveis agronômicas, produtividade de grãos, produtividade de massa seca (MS), densidade de plantas e altura de plantas para a cultura da soja.

\section{Material e Métodos}

\section{Área de estudo}

O trabalho foi realizado, no período de outubro de 2008 a abril de 2009, em uma propriedade rural no município de Ponta Grossa, estado do Paraná. O clima, segundo o sistema de Köppen, classificase como $C f b$, temperado, com temperatura média no mês mais frio abaixo de $18^{\circ} \mathrm{C}$ (mesotérmico), verões frescos, temperatura média no mês mais quente abaixo de $22{ }^{\circ} \mathrm{C}$ e sem estação seca definida (CAVIGLIONE et al., 2000). O solo foi classificado como CAMBISSOLO HÚMICO Alumínio típico (EMBRAPA, 2009).

\section{Índices pluviométricos}

Os índices pluviométricos foram medidos durante a condução do trabalho, utilizando 6 pluviômetros, distribuídos no interior da área estudo. Sendo que o total pluviométrico no ciclo da cultura foi de 565 $\mathrm{mm}$, distribuídos da seguinte forma, $35 \mathrm{~mm}$ em outubro, $48 \mathrm{~mm}$ em novembro, $80 \mathrm{~mm}$ dezembro, $227 \mathrm{~mm}$ janeiro, $125 \mathrm{~m}$ fevereiro e $50 \mathrm{~mm}$ março. 


\section{Implantação e manejo da cultura da soja}

A cultura da soja foi implantada, em uma área de 7,50 ha, utilizando-se a cultivar BRS 133. A semeadura foi realizada no dia 18 de outubro de 2008, em sistema de semeadura direta, sobre a resteva de aveia preta, previamente dessecada, utilizando-se o espaçamento entre linhas de 0,42 m e população inicial de 306.000 plantas ha-1.

No estabelecimento da cultura, foram retiradas amostras de solo para a realização da análise química conforme resultados: $\mathrm{pH}\left(\mathrm{CaCl}_{2}\right)$ : 5,0; fósforo (resina): $27 \mathrm{mg} \cdot \mathrm{dm}^{-3} ; \mathrm{H}+\mathrm{Al}: 6,2 \mathrm{cmol}$. $\mathrm{dm}^{-3}$; Al: 0,3 cmol.dm $\mathrm{dm}^{-3}$ K: 0,2 cmol.dm ${ }^{-3}$; Ca: 4,9 cmol.dm ${ }^{-3}$; Mg 2,4 cmol.dm ${ }^{-3}$; S.B.: 7,5 cmol.dm ${ }^{-3}$; C.T.C.: 13,7 cmol.dm ${ }^{-3}$; M.O.: 54 mg. $\mathrm{dm}^{-3}$. E com base nos resultados, foi realizada na semeadura, a adubação com $300 \mathrm{~kg} \mathrm{ha}^{-1}$ do adubo formulado NPK 00-20-20 e quarenta dias após a semeadura efetuou-se a adubação de cobertura com $100 \mathrm{~kg} \mathrm{ha}^{-1}$ de cloreto de potássio seguindo-se a recomendação proposta pela EMBRAPA 2001.

Avaliação do indice de vegetação da diferença normalizada (GNDVI)

Foram realizadas seis leituras do GNDVI em diferentes estádios fenológicos (EF): (12/12/08 EF V5, 24/12/08 EF V9, 06/01/09 EF R1, 15/01/09 EF R3, 29/01/09 EF R6 e 26/03/09 EF R8), utilizandose um sensor óptico ativo, modelo Crop Circle ${ }^{\circledR}$ ACS-210 (Holland Scientific), instalado na barra de um pulverizador hidráulico e, acoplados no trator, o coletor de dados modelo GeoSCOUT GLS-420 (com cartão de memória para armazenamento de dados), o GPS modelo SR20 da marca Leica, de precisão métrica (Figura 1) e a antena externa. O sensor fornece os valores de GNDVI, por meio da medição da reflectância do dossel nos comprimentos de onda de $590 \mathrm{~nm}$ (visível) e $880 \mathrm{~nm}$ (infravermelho próximo).
Figura 1. Sensor óptico ativo acoplado à barra de pulverização, coletor de dados e receptor GPS.

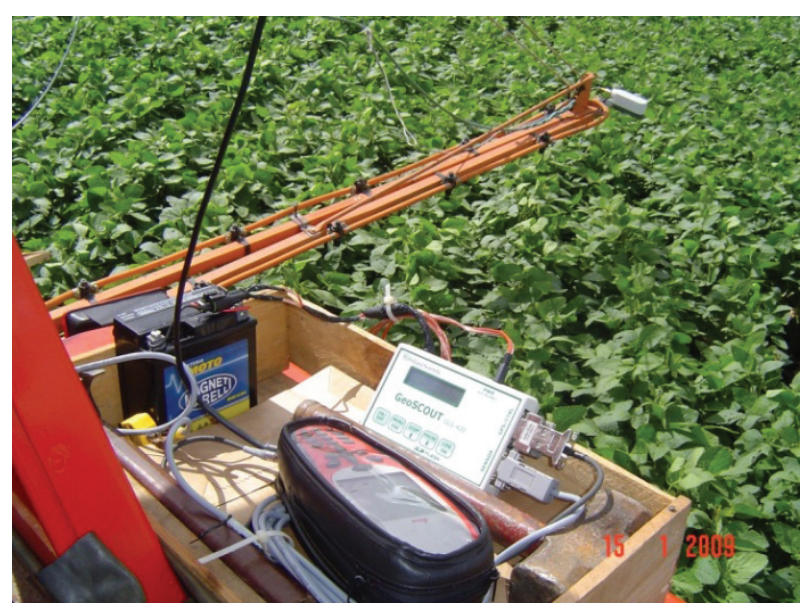

Fonte: Elaboração dos autores.

As leituras foram realizadas com passadas a cada $9 \mathrm{~m}$, respeitando-se as linhas de pulverização. A velocidade de deslocamento do trator foi ajustada a fim de gerar um ponto a cada $1 \mathrm{~m}$ totalizando, aproximadamente, 4.000 pontos na área total. Estes pontos foram interpolados pelo método da média simples, com resolução espacial de 5 x 5 m, utilizando-se o programa Spring 4.3.3. Com base na grade regular de pontos, gerados pela interpolação, amostrou-se, em torno de cada ponto georreferenciado, nove pontos para a leitura do GNDVI. Conforme especificação do fabricante, as leituras foram realizadas entre 0,80 e $1,20 \mathrm{~m}$ de altura do dossel (ápice da cultura), pois, neste intervalo, o sensor garante a qualidade da leitura (HOLLAND SCIENTIFIC, 2004).

\section{Determinação das variáveis agronômicas}

Produtividade de grãos

As avaliações das variáveis agronômicas seguiram os pontos georreferenciados distribuídos aleatoriamente, conforme a Figura 2. 
Figura 2. Pontos georreferenciados utilizados na coleta de amostras para as variáveis agronômicas: produtividade de grãos, produtividade de MS, densidade de plantas e altura de plantas.

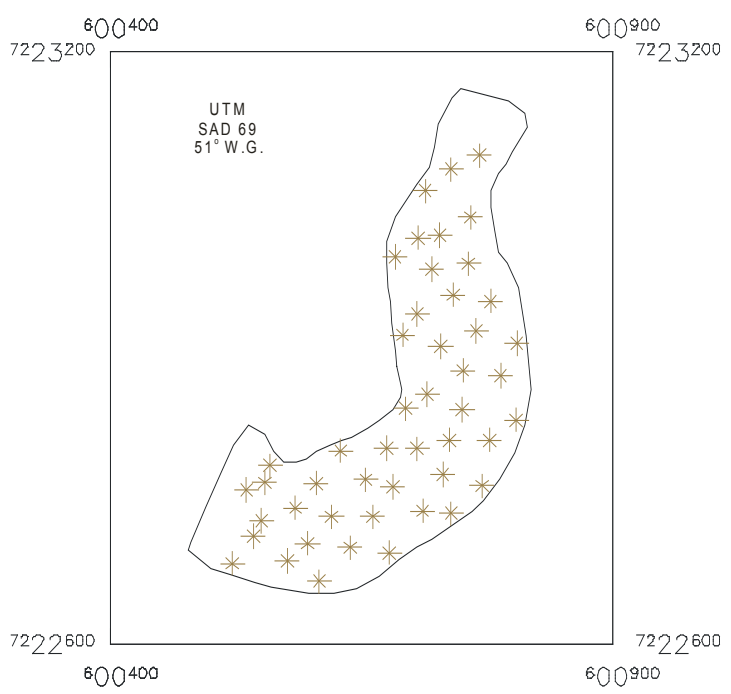

Fonte: Elaboração dos autores.

$\mathrm{Na}$ data de colheita de grãos (07/04/09) efetuou-se a amostragem para a determinação da produtividade. Foram colhidas plantas inteiras. Para tanto, mediu-se $1 \mathrm{~m}$ linear em cinco pontos distribuídos aleatoriamente em um raio de $15 \mathrm{~m}$, em torno de cada ponto georreferenciado. Depois de colhidas, as amostras foram acondicionadas em sacos de náilon, para posterior debulha. Em função da quantidade de material, a debulha foi realizada com o auxílio de uma debulhadora de cereais da marca NUX, modelo BC 80 II. Posteriormente, os grãos foram pesados em balança semi-analítica.

A umidade dos grãos foi determinada utilizandose um medidor eletrônico, portátil, modelo GEOLE-400. Este aparelho possui um recipiente onde foi realizada a pesagem da amostra. Esta amostra foi depositada no interior do medidor. A partir do valor da leitura no aparelho foi consultada uma tabela, que apresenta uma escala denominada "B" - Baixa Umidade em que se identifica a umidade dos grãos. O princípio da determinação é de capacitância elétrica, com base nas propriedades dielétricas que os grãos apresentam em diferentes teores de umidade. Posteriormente, ajustou-se a umidade para o padrão de $13,5 \%$ e, em seguida, calculou-se a produtividade de grãos $\left(\mathrm{t} \mathrm{ha}^{-1}\right)$.

\section{Produtividades de massa seca (MS)}

A avaliação da produtividade de MS foi realizada nos 48 pontos georreferenciados, seguindo-se os mesmos critérios descritos na coleta de amostras para a produtividade de grãos. As amostragens para esta variável foram realizadas após cada leitura do GNDVI.

As amostras foram pesadas (em dinamômetro) e, em seguida, retirada uma subamostra para secagem em estufa com circulação forçada de ar à temperatura de $60^{\circ} \mathrm{C}$ por, aproximadamente, $72 \mathrm{~h}$. Após a secagem, o material foi novamente pesado e a produtividade de MS ( $\left.\mathrm{t} \mathrm{ha}^{-1}\right)$ calculada.

\section{Densidade de plantas}

A determinação da densidade de plantas (plantas por metro linear) foi realizada em três datas de leitura do GNDVI (12/12/08, 24/12/08 e 26/03/09).

A coleta das amostras para a determinação da densidade de plantas foi efetuada em 48 pontos georreferenciados. Mediu-se $1 \mathrm{~m}$ linear em cinco pontos distribuídos, aleatoriamente, em um raio de $15 \mathrm{~m}$, em torno de cada ponto georreferenciado.

\section{Altura de plantas}

Em todas as datas de leitura do GNDVI, foi medida a altura das plantas. A amostragem foi realizada em 48 pontos georreferenciados. Foram efetuadas dez medidas de altura, em torno de cada ponto georreferenciado, distribuídas em um raio de 15 m. A medição foi realizada, com o auxílio de uma trena, considerando-se a altura da planta do solo até seu ápice. 


\section{Análises estatisticas}

Realizou-se a análise de regressão entre os pontos de amostragem, para cada variável agronômica, e as leituras do GNDVI em cada data de avaliação, utilizando o programa Statistica 8.0, a fim de verificar quais variáveis agronômicas estabeleciam grau de relação com o GNDVI. Em seguida, aplicouse o teste $\mathrm{F}$ com níveis de significância de 1 e 5\% para o ângulo alfa, da equação de regressão, para verificar quais as variáveis agronômicas poderiam ser quantificadas por meio das leituras do GNDVI.

\section{Resultados e Discussão}

GNDVI versus produtividade de grãos

De acordo com Ma et al. (2001), Antuniassi; Baio; Sharp (2007), existe correlação positiva entre a reflectância do dossel das plantas, expressa em valores de NDVI, e a produtividade das culturas. No entanto, no presente estudo, com base nos coeficientes de determinação $\left(\mathrm{r}^{2}\right)$, observou-se correlação entre a produtividade de grãos e o GNDVI somente para o EF V9. Para os demais EF, a correlação foi pouco expressiva, como pode ser verificado na Tabela 1.

Tabela 1. Resultado da regressão entre o GNDVI e a produtividade de grãos.

\begin{tabular}{|c|c|c|c|c|}
\hline \multicolumn{2}{|c|}{ Variáveis } & \multirow{2}{*}{ Equações } & \multirow{2}{*}{$\mathrm{r}^{2}$} & \multirow[b]{2}{*}{$\mathrm{p}$} \\
\hline Dependente & Independente & & & \\
\hline \multirow{6}{*}{ Produtividade } & GNDVI V5 & $\mathrm{y}=2,8929 \mathrm{x}+1,418^{* *}$ & 0,16 & 0,00 \\
\hline & GNDVI V9 & $\mathrm{y}=7,5610 \mathrm{x}-1,840^{* *}$ & 0,59 & 0,00 \\
\hline & GNDVI R1 & $y=4,5236 x-0,234^{*}$ & 0,09 & 0,03 \\
\hline & GNDVI R3 & $y=5,8861 x-1,406$ & 0,04 & $\mathrm{~ns}$ \\
\hline & GNDVI R6 & $y=6,4586 x-1,8316^{*}$ & 0,10 & 0,02 \\
\hline & GNDVI R8 & $y=1,2237 x+2,476$ & 0,01 & $\mathrm{~ns}$ \\
\hline
\end{tabular}

ns: não-significativo. * e $* *$ Significativo a 5 e $1 \%$ de probabilidade, respectivamente.

Fonte: Elaboração dos autores.

No EF V5, o baixo coeficiente de determinação pode ter resultado da grande interferência do solo nesta fase. Conforme Dalmolin et al. (2005), vários elementos que compõem a superfície do solo (matéria orgânica, textura, composição mineralógica, rugosidade e umidade) podem afetar a reflectância do dossel e, por consequência, o GNDVI. Esse conjunto de elementos é denominado de "superfície de fundo" (HUETE, 1985). Esta superfície de fundo, presente na entre linha da cultura quando a mesma ainda não fechou completamente, interfere na resposta espectral do dossel que, por sua vez, afeta a determinação do GNDVI.

A partir do EF R1, os baixos valores encontrados nos coeficientes de determinação podem resultar do pleno desenvolvimento da cultura, que faz com que a reflectância torne-se homogênea saturando o GNDVI. Esta observação está de acordo com Myneni et al. (2002) que analisaram o NDVI para diferentes dosséis, e verificaram que a saturação não permite a diferenciação de zonas que caracterizem a variação do dossel e que possam ser correlacionadas com a produtividade.

No EF V9, o coeficiente de determinação observado foi de 0,59 , pois nesse estádio a cultura encontrava-se no pleno desenvolvimento e sem a presença de flores que poderiam influenciar a resposta espectral do dossel. Assim, para se estabelecer a correlação das medidas de GNDVI com a produtividade de grãos, recomenda-se que as leituras sejam realizadas neste estádio fenológico. Esse é um fator que limita o uso deste índice para a estimativa da produtividade, pois eventos que ocorram posteriormente a este EF não serão 
quantificados, como, p.e., o ataque de pragas, as doenças e outros danos ocasionados por fenômenos climáticos.

Batista; Rudorff; Oviedo (1988) avaliaram duas cultivares de soja e encontraram coeficiente de determinação superior $(0,76)$. Ma et al. (2001) também observaram coeficiente de determinação superior, de 0,80 no EF R5. Porém Holzapfel (2007), avaliando a correlação entre o NDVI e a produtividade de grãos de canola, obteve coeficientes de determinação, em diferentes $\mathrm{EF}$, variando entre 0,00 e 0,63 , para o ano de 2005 e de 0,25 a 0,53 para o ano de 2006, mostrando que as relações variam de um ano para o outro no mesmo EF.

Rudorff et al. (2003) avaliaram o NDVI na estimativa da produtividade de milho e observaram que não houve relação direta entre o NDVI e a produtividade de grãos para produtividades acima de $5 \mathrm{t} \mathrm{ha}^{-1}$. Estes autores atribuíram a limitação do uso do NDVI, na estimativa de produtividades superiores a $5 \mathrm{t} \mathrm{ha}^{-1}$, ao elevado índice de área foliar (IAF). Entretanto, isto deve ser visto com cuidado uma vez que os valores de IAF variaram de 2,0 a 4,5, ou seja, aquém da saturação do NDVI para o milho. Macedo e Rudorff (2003) observaram que o NDVI explicou $54 \%$ da variação na produtividade de grãos do milho safrinha, e os valores de NDVI variaram de 0,60 a 0,90 e a produtividade de 0,5 a $5,0 \mathrm{tha}^{-1}$.

\section{GNDVI versus produtividade de massa seca}

De acordo com os coeficientes de determinação $\left(\mathrm{r}^{2}\right)$, observou-se melhor correlação entre a produtividade de MS e o GNDVI somente para o EF V9 (Tabela 2), assim como observado para a produtividade de grãos (Tabela 1). No entanto, os valores de correlação foram menores. Como, de certa forma, a produtividade de grãos depende da produtividade de MS, era de se esperar que ocorresse o mesmo comportamento. Santos Júnior et al. (2001) observaram, para a cultura da soja, relação da produtividade de massa com o NDVI.

Tabela 2. Resultado da regressão entre o GNDVI e a produtividade de massa seca (MS).

\begin{tabular}{|c|c|c|c|c|}
\hline \multicolumn{2}{|c|}{ Variáveis } & \multirow{2}{*}{ Equações } & \multirow{2}{*}{$\mathrm{r}^{2}$} & \multirow{2}{*}{$\mathrm{p}$} \\
\hline Dependente & Independente & & & \\
\hline \multirow{6}{*}{ MS } & GNDVI V5 & $y=2,8638 x+3,6094(*)$ & 0,04 & 0,04 \\
\hline & GNDVI V9 & $\mathrm{y}=12,485 \mathrm{x}-1,0747(* *)$ & 0,28 & 0,00 \\
\hline & GNDVI R1 & $y=7,8714 x+3,2841$ & 0,04 & ns \\
\hline & GNDVI R3 & $y=14,197 x-0,8292$ & 0,02 & ns \\
\hline & GNDVI R6 & $y=20,688 x-5,3701$ & 0,10 & ns \\
\hline & GNDVI R8 & $y=6,3323 x+7,0779$ & 0,03 & ns \\
\hline
\end{tabular}

ns: não-significativo. * e ** Significativo a 5 e $1 \%$ de probabilidade, respectivamente.

Fonte: Elaboração dos autores.

Os menores coeficientes de determinação, principalmente nos estádios mais avançados de desenvolvimento da cultura ( $\mathrm{R} 1 \mathrm{em}$ diante), devemse ao fato que a soja, nessas fases, apresentar saturação do GNDVI e a reflectância é proveniente apenas das folhas superiores. De acordo com Moreira (2007), a inserção foliar regula o grau de penetração da radiação no interior do dossel e a soja, por ser uma planta de inserção foliar planófila e/ou intermediária, após determinado estádio fenológico, a reflectância resulta apenas da parte superior do dossel, o que gera limitações para a utilização do NDVI. Porém se fosse utilizado o índice de clorofila proposto por Gitelson; Kaufman; Merzlyar (1996), talvez melhores relações seriam encontradas. 
No entanto, Epstein et al. (2005), usando imagens de satélite para medição do NDVI e sua relação com a produtividade de massa de gramíneas, obtiveram coeficiente de determinação mais elevado $(0,60)$ que os obtidos nesse estudo. Brandão et al. (2007) utilizaram imagens de satélite, provenientes do LANDSAT, para avaliarem a relação entre o NDVI e a massa total, de quatro tipos de vegetação no Estado do Ceará: vegetação semidensa, densa, nativa e rala, e encontraram elevados coeficientes de determinação, respectivamente, 0,90, 0,99, 0,80 e 0,74. Lamb; Trotter; Schneider (2009) avaliaram a massa de sorgo (Sorghum bicolor), usando sensor ativo Crop Circle ${ }^{\circledR}$, e obtiveram coeficiente de determinação de 0,90. Hancock e Dougherty (2007), avaliando o NDVI, em alfafa, e sua relação com a MS produzida encontraram $r^{2}$ de 0,58 .

Nos trabalhos anteriormente citados, para diversas culturas, encontrou-se $r^{2}$ elevado, assim, pode-se afirmar que existe potencial para o uso do NDVI na estimativa da produtividade de MS, porém, no presente trabalho, para a cultura da soja, isso não foi observado.

\section{GNDVI versus densidade de plantas}

Para todos os EF avaliados, os coeficientes de determinação foram baixos $(0,0036$ a 0,0891) o que está de acordo com Araújo (2004), que obteve $\mathrm{r}^{2}$ de 0,0838 avaliando a relação entre a densidade de plantas e o NDVI, obtidos por videografia aérea para a cultura da soja.

De acordo com Mercante et al. (2009), baixos valores para a cultura da soja podem ocorrer em função do hábito de crescimento indeterminado e da alta capacidade de compensar falhas no estande, pela emissão de ramos laterais. Sendo assim, este fator pode limitar a percepção das mudanças do GNDVI, quando existe variação na densidade de plantas.

Phillips et al. (2004) utilizaram os valores de NDVI, para estimar a densidade de plantas de trigo, e obtiveram $\mathrm{r}^{2}$ de 0,74 ; essa correlação foi conseguida apenas até a população de 1.000 plantas $\mathrm{m}^{-2}$, a partir dessa população, o NDVI não foi considerado um estimador da densidade. Ma et al. (2001), estudando três densidades de plantas de soja, em duas texturas de solo (arenosa e argilosa) e em dois anos consecutivos, concluíram que a densidade de plantas não apresenta relação com o NDVI. Já Ahmadi e Mollazade (2009), avaliando o NDVI, obtido por imagens de satélite, encontraram boa correlação para a densidade de plantas de soja $\left(r^{2}=0,87\right)$.

\section{GNDVI versus altura das plantas}

Para a altura das plantas, os coeficientes de determinação foram baixos $(0,00005$ a 0,06600$)$ assim como observado para a densidade de plantas. Não houve relação entre o GNDVI e a altura das plantas nos EF avaliados.

Araújo (2004) avaliando o NDVI com videografia aérea na cultura da soja, obteve $r^{2}$ de $0,14(p<0,01)$ o que demonstra a limitação do uso do NDVI na estimativa da altura das plantas. Xavier et al. (2006), ao avaliarem a altura de plantas de trigo, encontraram $r^{2}$ de 0,68 , na fase de espigamento da cultura. Já Motomiya; Molin; Chiavegato (2009), avaliando a relação entre o NDVI e a altura de plantas de algodão, encontraram $r^{2}$ de 0,74 .

Isso pode estar relacionado ao espaçamento da cultura, uma vez que para o algodão o espaçamento entre linhas é maior e, assim, a cultura não fecha por completo, permitindo que a reflectância, maior ou menor, seja caracterizada pelo NDVI, sendo possível estabelecer relações entre este e a altura, o que não ocorreu para a cultura da soja.

\section{Conclusões}

O GNDVI na cultura da soja estabeleceu correlações significativas apenas com a produtividade de grãos e a produtividade de MS no 
EF V9. Assim, para se estabelecer a correlação do GNDVI com essas variáveis recomenda-se que as leituras sejam realizadas nesse EF.

\section{Referências}

AHMADI, H.; MOLLAZADE, K. Determination of soya plant population using NDVI in the dasht e naz agriindustry. Journal of Agricultural Science, Toronto, v. 1, n. 1 p. 112-120, 2009.

ALMEIDA, T. S. Respostas espectrais da soja sob diferentes condições hídricas e de preparo de solo. 2008. Dissertação (Mestrado em Sensoriamento Remoto) - Universidade Federal do Rio Grande do Sul, Porto Alegre.

ANTUNIASSI, U. R.; BAIO, F. H. R.; SHARP, T. C. Agricultura de Precisão. In: CONGRESSO BRASILEIRO DO ALGODÃO, 6., 2007, Uberlândia. Anais... Uberlândia: CNPA, 2007. p. 11-21.

ARAÚJO, J. C. Determinação de zonas de manejo e estimativa da produtividade de culturas de grãos por meio de videografia aérea digital multiespectral. 2004. Tese (Doutorado em Irrigação e Drenagem) - Escola Superior de Agricultura Luiz de Queiroz, Piracicaba.

BATISTA, G. T.; RUDORFF, B. F. T.; OVIEDO, A. F. P. Resposta espectral da soja e sua relação com parâmetros agronômicos. In: SIMPÓSIO BRASILEIRO DE SENSORIAMENTO REMOTO, 5., 1988, Natal. Anais... São José dos Campos: INPE, 1988. p. 406-413.

BRANDÃO, Z. N.; BEZERRA, M. V. C.; SILVA, B. B. Uso do NDVI para determinação da biomassa na chapada do Araripe. In: SIMPÓSIO BRASILEIRO DE SENSORIAMENTO REMOTO, 13., 2007, Florianópolis. Anais... Florianópolis: INPE, 2007. p. 7581.

CAVIGLIONE, J. H.; KIIHL, L. R. B.; CARAMORI, P. H.; OLIVEIRA, D.; GALDINO, J.; BORROZINO, E.; GIACOMINI, C. C.; SONOMURA, M. G. Y.; PUGSLEY, L. Cartas climáticas do Paraná. Londrina: IAPAR, 2000. CD-ROM.

COMPANHIA NACIONAL DE ABASTECIMENTO CONAB. Acompanhamento de safra brasileira: grãos, décimo segundo levantamento, setembro/2012. Brasília: Conab, 2012. $30 \mathrm{p}$.

DALMOLIN, R. S. D.; GONÇALVES, C. N.; KLAMT, E.; DICK, D. P. Relação entre os constituintes do solo e seu comportamento espectral. Ciência Rural, Santa Maria, v. 35, n. 2, p. 481-489, 2005.
EMBRAPA BRASILEIRA DE PESQUISA AGROPECUÁRIA. Tecnologias de Produção de Soja Paraná - 2001/2002 Embrapa Soja. Londrina: Embrapa Soja, 2001. 281 p. (Documentos/Embrapa Soja, n. 166).

Atualização do mapa de solos SiBCS. In:

Carta de solos do estado do Paraná. Curitiba: Embrapa Solos, 2009.

EPSTEIN, H. E.; WALKER, D. A.; JIA, G. J.; KELLEY, A. M. Climate, plant biomass, NDVI and LAI relationships along the full arctic bioclimate gradient. American Geophysical Union, Washington, v. 23, n. 13, p. 1012-1024, 2005.

FONTANA, D. C.; WEBER, E.; DUCATI, J. R.; BELARTO, M. A; GUASSELLI, L. A. ; GUSSO, A. Monitoramento da cultura da soja no centro-sul do Brasil durante La Niña de 1998/2000. Revista Brasileira de Agrometeorologia, Santa Maria, v. 10, n. 2, p. 343-351, 2002.

FORMAGGIO, A. R.; EPIPHANIO, J. C. N. Estudo radiométrico das culturas de trigo e de feijão em três tipos de latossolos. In: SIMPÓSIO BRASILERIO DE SENSORIAMENTO REMOTO, 5., Natal, 1988. Anais... São José dos Campos, INPE, 1988. p. 405-410.

GENÚ, A. M.; DEMATTÊ, J. A. M.; FIORIO, P. R. Análise espectral de solos da Região de Mogi-Guaçú (SP). Semina: Ciências Agrárias, Londrina, v. 31, p. 1235-1244, 2010. Suplemento 1.

GITELSON, A. A.; KAUFMAN, Y.; MERZLYAR, M. $\mathrm{N}$. Use of green channel in remote sensing of gloval vegetation fron EOS-MODIS. Remote Sensing of Environment, v. 58, p. 289-298, 1996. Disponível em: $<$ http://dx.doi.org/10.1016/S0034-4257(96)00072-7>. Acesso em: 15 jun. 2012.

HANCOCK, D. W.; DOUGHERTY, C. T. Relationships between blue- and red-based vegetation indices and leaf area and yield of alfalfa. Crop Science, Madison, v. 47, n. 6, p. 2547-2556, 2007.

HOLLAND SCIENTIFIC INSTRUCTION MANUAL ACS 210. Plant canopy reflectance sensor manual. Revision 1.0 August 23, 2004.

HOLZAPFEL, C. B. Estimating nitrogen fertilizer requirements of canola (Brassica napus L.) using sensorbased estimates of yield potential and crop response to nitrogen. 2007. Thesis (Master of Science) Faculty of Graduate Studies of the University of Manitoba.

HUETE, A. R. Spectral response of a plant canopy with different soil background. Remote Sensing of Environment, New York, v. 17 p. 37-53, 1985. 
LAMB, D. W.; TROTTER, M. G.; SCHNEIDER, D. A. Measuring and mapping crop vigour using an active optical sensor in an ultra low level aircraft. In: SYMPOSIUM ON PRECISION AGRICULTURE IN AUSTRALASIA, 13., 2009, Amidale. Proccedings... Armidale: University of New England, 2009. p. 31-40.

MA, B. L.; DWYER, L. M.; COSTA, C.; COBER, E. R.; MORRISON, M. J. Early prediction of soybean yield from canopy reflectance measurements. Agronomy Journal, Madison, v. 93, n. 6, p. 1227-1234, 2001.

MACEDO, M. A.; RUDORFF, B. F. T. Geotecnologias no seguro agrícola do milho safrinha. Agricultura em São Paulo, São Paulo, v. 50, n. 1, p. 43-52, 2003.

MACHADO, H. M. Determinação da biomassa de cana-de-açúcar considerando a variação espacial de dados espectrais do satélite LANDSAT 7 - ETM+. 2003. Dissertação (Mestrado em Engenharia Agrícola) - Faculdade de Engenharia Agrícola. Universidade Estadual de Campinas, Campinas.

MERCANTE, E.; LAMPARELLI, R. A. C.; URIBEOPAZO, M. A.; ROCHA, J. V. Características espectrais da soja ao longo do ciclo vegetativo com imagens landsat 5/TM em área agrícola no Oeste do Paraná. Engenharia Agrícola, Jaboticabal, v. 29, n. 2, p. 328-338, 2009.

MOREIRA, M. A. Fundamentos do sensoriamento remoto e metodologias de aplicação. 3. ed. São José dos Campos: Universidade Federal de Viçosa, 2007.

MOTOMIYA, A. V. A.; MOLIN, J. P.; CHIAVEGATO, E. J. Utilização de sensor óptico ativo para detectar deficiência foliar de nitrogênio em algodoeiro. Revista Brasileira Engenharia Agrícola Ambiental, Campina Grande, v. 13, n. 2, p. 137-145, 2009.

MOTTA, J. L. G.; FONTANA, D. C. Verificação da acurácia da estimativa de área cultivada com soja através de classificação digital em imagens Landsat. In: SIMPÓSIO BRASILEIRO DE SENSORIAMENTO REMOTO, 5., 2001, Foz do Iguaçu. Anais... Foz do Iguaçu: INPE, 2001. p. 123-129.

MYNENI, R. B.; KNYAZIKHIN, Y.; PRIVETTE, J. L.; GLASSY, J.; TIAN, Y.; WANG, Y.; SONG, X.; ZHANG, Y.; SMITH, G. R.; LOTSCH, A.; FRIEDL, M.; MORISETTE, J. T.; VOTAVA, P.; NEMANI, R. R.; RUNNING, S.W. Global products of vegetation leaf area and fraction absorbed PAR from year one of MODIS data. Remote Sensing of Environment, New York, v. 28, n. 2, p. 214-231, 2002.
NANNI, M. R.; DEMATTÊ, J. A. M.; FIORIO, P. R. Soil discrimination analysis by spectral response in the ground level. Pesquisa Agropecuária Brasileira, Brasília, v. 39, n. 10, p. 995-1006, 2004.

PHILLIPS, S. B.; KEAHEY, D. A.; WARREN, J. G.; MULLINS, G. L. Estimating winter wheat tiller density using spectral reflectance sensors for early-spring, variable-rate nitrogen applications. Agronomy Journal, Madison, v. 96, n. 3, p. 591-600, 2004.

RUDORFF, B. F. T.; MOREIRA, M. A.; ADAMI, M.; FREITAS, J. G. Resposta espectral do milho e sua relação com altos níveis de produtividade de grãos. In: SIMPÓSIO BRASILEIRO DE SENSORIAMENTO REMOTO, 11., Belo Horizonte. Anais... Belo Horizonte: INPE, 2003. p. 2597-2603.

SANTOS JÚNIOR, R. F.; SANTOS, J. M.; RUDORFF, B. F. T. MARCHIORATO, I. A. Espectrorradiometria de campo no visível e infravermelho próximo para detecção de áreas infestadas com Meloidogyne javanica em soja. In: CONGRESSO BRASILEIRO DE NEMATOLOGIA, 23., 2001, Marília. Anais... Marília: [s.n.], 2001. p. 62-62.

SHANAHAN, J. F.; SCHEPERS, J. S.; FRANCIS, D. D.; VARVEL, G. E.; WILHELM, W.; TRINGE, J. M.; SCHLEMMER, M. R.; MAJOR, D. Use of Remotesensig imagery to estimate corn grain yield. Agronomy Faculty Publications, 2001. Paper 9. Disponível em: $<$ http://digitalcommons.unl.edu/agronomyfacpub/9>. Acesso em: 15 jun. 2012.

SUGAWARA, L. M.; RUDORFF, B. F.; ADAMI, M. Viabilidade de uso de imagens Landsat em mapeamento de área cultivada com soja no Estado do Paraná. Pesquisa Agropecuária Brasileira, Brasília, v. 43, n. 12, p. $1777-$ 1783, dez. 2008.

XAVIER, A. C.; RUDORFF, B. F. T.; MOREIRA, M. A.; ALVARENGA, B. S.; FREITAS, J. D.; SALOMON, M. V. Hyperspectral field reflectance measurements to estimate wheat grain yield and plant height. Scientia Agricola, Piracicaba, v. 63, n. 2, p. 130-138, 2006. 
